\title{
Epidemiological and clinical profiles of respiratory syncytial virus infection in hospitalized neonates in Suzhou, China
}

Lianghua $\mathrm{Lu}^{1 \dagger}$, Yongdong Yan ${ }^{2 \dagger}$, Bin Yang ${ }^{3}$, Zhihui Xiao ${ }^{1}$, Xing Feng ${ }^{1}$, Yuqing Wang ${ }^{2}$, Wei $\mathrm{Ji}^{2}$, Maximillion Mize ${ }^{4}$, Chuangli $\mathrm{HaO}^{2^{*}}$ and Zhengrong Chen ${ }^{2^{*}}$

\begin{abstract}
Background: This study was designed to explore the epidemiological and clinical profiles of respiratory syncytial virus (RSV) infection in neonates from the Suzhou area of China, taking into consideration how climate factors influence disease.

Methods: From 2010 to 2014, nasopharyngeal aspirates (NPA) collected from hospitalized neonates with lower respiratory tract infections (LRIs) were screened for seven common respiratory viruses including RSV by direct immunofluorescence assay. Human bocavirus, human metapneumovirus, and mycoplasma pneumoniae were detected by polymerase chain reaction.

Results: Of the 1803 hospitalized neonates analyzed, $20.74 \%$ were found to be infected with RSV. Interestingly, 30 subjects were identified as being coinfected with other viruses. The rate of RSV infection was highestduring thewinter and early spring seasons; however, infection was negatively associated with monthly mean temperature $\left(r_{s}=-0.821, P<0.0001\right)$, total rainfall $\left(r_{s}=-0.406, P=0.002\right)$, and sum of sunshine $\left(r_{s}=-0.386, P=0.001\right)$. Monthly mean temperature was the only independent factor associated with RSV activity, as determined using multivariate regression analysis. Compared with non-RSV neonates, neonates with RSV infection presented more frequently with tachypnea,moist rales, and abnormal chest $\mathrm{X}$-rays requiring supplemental oxygen and extended hospitalization postpartum. Neonatal admittance into the NICU was determined based on prematurity and coinfection with other viruses; two independent risk factors for RSV disease, as determined by multivariate logistic analysis.
\end{abstract}

Conclusions: Important as a major cause of LRIs in hospitalized neonate, we found that the subtropical climate of the Suzhou area was associated with RSV activity. The identified risk factors ofsevere disease in neonates with RSV infection should be taken into consideration when implementing disease health interventions.

Keywords: Lower respiratory tract infection, Neonate, Respiratory syncytial virus, Climate factors, Severity

\section{Background}

Respiratory syncytial virus (RSV) is a leading cause of acute respiratory tract infections in infants and young children, with an estimated 3.4 million hospitalizations and 0.6 million deaths reported annually worldwide $[1,2]$. Because of the limited antibody response and reduced concentration of passively acquired maternal antibodies in

\footnotetext{
*Correspondence: hcl_md@163.com; chen_zheng_rong@163.com

†Equal contributors

2Department of Respiratory Disease, Children's Hospital of Soochow University, Suzhou 215003, China

Full list of author information is available at the end of the article
}

neonates, preterm neonates are highly susceptible to RSV [3]. In addition, with the lacki of an effective vaccine, neonates and newborns are more prone to lower respiratory tract infections (LRIs) caused by RSV. Accounting for $81 \%$ of all pneumonia cases diagnosed as viral communityacquired pneumonia (CAP), RSV has been associated with significant morbidiy and mortality among neonates [4].

Few studies have focused on the burden of neonatal RSV infection in China. However, past studies have reported on the prevalence and clinical characteristics of RSV infection in children over 2 months old. Therefore, the purpose of this study was to explore the epidemiological and clinical 
profiles of neonates presenting with RSV infection in Suzhou China and paying close attention to the association between infection and climate factors.

\section{Methods}

\section{Study population}

This study was conducted at Children's Hospital of Soochow University, the only comprehensive tertiary children hospital serving most young children in Suzhou. From January 2010 to December 2014, nasopharyngeal aspirates (NPA) were collected within $24 \mathrm{~h}$ from all hospitalized neonates ( $\leq 28$ days) who were diagnosed with LRIs (either bronchiolitis or pneumonia). Lower respiratory tract infection was defined as: the presence of wheezing, tachypnea, chest retractions, abnormal auscultatory findings (wheezing and crackles), the presence of fever, and radiologic evidence indicative of a LRI. Chest radiography was performed using standard equipment and radiographic techniques, and reviewed by the radiologists in digital format. Low birth weight was considered $<2500 \mathrm{~g}$ for the present study.

All NPAs were immediately sent to the laboratory to assess the presence of RSV as determined by direct immunofluorescent assay (DFA). This study was approved by the Ethics Committee of Children's Hospital of Soochow University, and consent forms were obtained from the guardians for all children enrolled in this study.

\section{Data collection}

Data on patient demography, clinical symptoms, complications, underlying diseases (i.e. congenital heart disease, bronchopulmonary dysplasia, bronchopulmonary malformation, Down's Syndrome) and laboratory findings (including radiographic outcomes) were obtained from the hospital medical records system.

\section{Detection of common respiratory pathogens}

Seven common respiratory viruses were detected by DFA (D3 Ultra DFA respiratory virus screening and identification kit, Athens, Ohio, USA). Nasal passage aspirates, were collected as previously described, with sample from each neonate divided into two sections for detection of viral species by DFA and PCR, respectively. All freshly made slides with smears of exfoliated cells were used for viral antigen detection (RSV, influenza virus (IV-A and IV-B), parainfluenza virus (type 1, 2, 3) and adenovirus) as described previously [5].

Human bocavirus and metapneumovirus, as well asMycoplasma pneumoniae, were detected by PCRs as previously described [6]. Briefly, the other half of a patient NPA was used for DNA or RNA extraction. Samples were centrifuged at $12,000 \times \mathrm{g}$ for $5 \mathrm{~min}$, followed by extraction of DNA and RNA from a 400- $\mu$ l sample using DNA-EZ Reagents (Sangon Biotech,
Shanghai, China) or TRIzol Reagent (Life Technologies, Carlsbad, USA) in accordance with the manufacturer's instructions. A final volume of $200-\mu \mathrm{l}$, containing either DNA or RNA, was eluted anddivided into two aliquots for detection of human bocavirus and Mycoplasma pneumoniae gene amplification via realtime PCR. RNA sample was used for human metapneumovirus gene amplification via reverse transcription PCR.

\section{Climate data collection}

Climate data (monthly mean temperature $\left({ }^{\circ} \mathrm{C}\right)$, relative humidity (\%), total rainfall $(\mathrm{mm})$, sum of sunshine (h), and wind velocity $(\mathrm{m} / \mathrm{s})$ were provided by the Meteorological Bureau of Suzhou at longitude $120^{\circ} 6^{\prime}$ east and latitude $31^{\circ} 3^{\prime}$ north, which is located $8 \mathrm{~km}$ away from the Children's Hospital of Soochow University.

\section{Statistical analysis}

Statistical analysis was performed using SPSS v.17.0 for Windows (SPSS Inc., Chicago, IL). Discreet data were analyzed using the Chi-square test. Continuous data were analyzed using the T-test for normally distributed data, while the Kruskal-Wallis test was used to analyze data that failed to show a normal distribution. The association between RSV cases and climate factors were analyzed using the Spearman correlation test. To detect interactions among the climate factors multivariate regression analysis was used. All tests were two-tailed with $P<0.05$ considered statistically significant.

\section{Results}

\section{Incidence and demography of all neonates with RSV} infection

From 2010 to 2014, a total of 1803 NPAs from neonates hospitalized with LRTs were obtained to detect viruses and Mycoplasma pneumoniae. Of all 1803 caseswith LRTs, 374 cases were confirmed with RSV, 75 with IVA, 45 with M. pneumoniae, 15 with PIV-3, 10 with IV-B, 10 with ADV, 5 with $\mathrm{HBoV}$, and 3 with hMPV. Accounting for $20.74 \%(374 / 1803)$ of all LRT cases, RSV was the most commonly identified respiratory virus in our samples. A total of 163 cases were identified as being infected with other viruses not listed here; this includes 30 cases in which patients were coinfected with RSV and another respiratory patohgen. As shown in Table 1, IV-A was the most common virus that established coinfection with RSV in neonates.

Among the 374 cases of RSV infection, the youngest neonate was 5 days old and the oldest was 28 days postdelivery; the median age was 17 days old. Age distribution of RSV-positive neonates is shown in Fig. 1. This data indicates that the incidence of RSV-positive neonates increases with age. Of all 374 cases of RSV infection, 224 $(59.9 \%)$ neonates were male yielding a male: female ratio 
Table 1 Distribution of co-infection with RSV

\begin{tabular}{lll}
\hline Co-infection distribution & Positive number & Percent \\
\hline Co-infection with RSV & 12 & \\
Influenza virus A & 8 & 40.0 \\
Mycoplasma pneumoniae & 5 & 26.7 \\
Influenza virus B & 2 & 16.7 \\
Parainfluenza virus type 3 & 1 & 6.7 \\
Human metapneumovirus & 1 & 3.3 \\
Humna bocavirus & 1 & 3.3 \\
Adenovirus & 30 & 3.3 \\
Total co-infection & & 100 \\
\hline
\end{tabular}

$R S V$ respiratory syncytial virus

of 1.49:1. Compared to the male: female ratio of other viral infections (1.67:1), no significant difference was found in gender between RSV-positive neonates and neonates testing positive for other viruses $(P>0.05)$. Only 28 cases $(7.5 \%, 28 / 374)$ were reported to have a gestational age less than 37 weeks and most of RSV-positive neonates grew to full term.

\section{Seasonal and monthly distribution of neonates with RSV infection}

From 2010 to 2014, the annual RSV incidences were 8.2 (46/562), 18.8 (79/420), 6.8 (70/515), 13.6 (53/419), and $31.0 \%(126 / 406)$ respectively. High incidence was found in the year $2014(P<0.05)$, especially in December. Infection with RSV mainly occurred in winter and early spring (December to May), and prevailed from November to April, with a peak from December to February each year. RSV-positive cases were rarely observed each year during summer (June to August) with theexception of the year 2014 (Fig. 2).

\section{Association between RSV infection and climate factors}

From 2010 to 2014, the monthly mean temperature was $17.3 \pm 8.8$ (mean \pm S.D.) ${ }^{\circ} \mathrm{C}$, relative humidity was $71.0 \pm$ $6.8 \%$, total rainfall was $90.1 \pm 64.7 \mathrm{~mm}$, sum of sunshine was $156.3 \pm 50.8 \mathrm{~h}$, and wind velocity was $2.2 \pm 0.5 \mathrm{~m} / \mathrm{s}$. The monthly mean data for climate factors are shown in Fig. 2. Associations between RSV-positive neonates and climate factors were explored by Spearman rank correlations. Monthly mean temperature, sum of sunshine and total rainfall were significantly correlated with the number of RSV-positive neonates with LRIs $(P<0.05)$. The spearman correlation coefficients are $-0.821,-0.406$, and -0.386 , respectively. Having the lowest seasonal temperatures of the year, RSV activity was reported to be at its highest during the winter months.

In light of intercorrelations among these climate factors, multivariateregression analysis was used to analyze the associations between the number of RSV-positive cases and our chosen climate factors. Monthly mean temperature was the only independent factor shown to be associated with the number of RSV-positive cases (Table 2).

\section{Clinical and laboratory characteristics in neonates with RSV infection}

Clinical and laboratory characteristics in neonates suffering solely of RSV infection are summarized in Table 3. Compared toneonates infected with viruses, RSV-positive neonates were younger and presented more frequently with tachypnea, moist rales, and abnormal chest X-ray requiring supplemental oxygen and an extended hospital

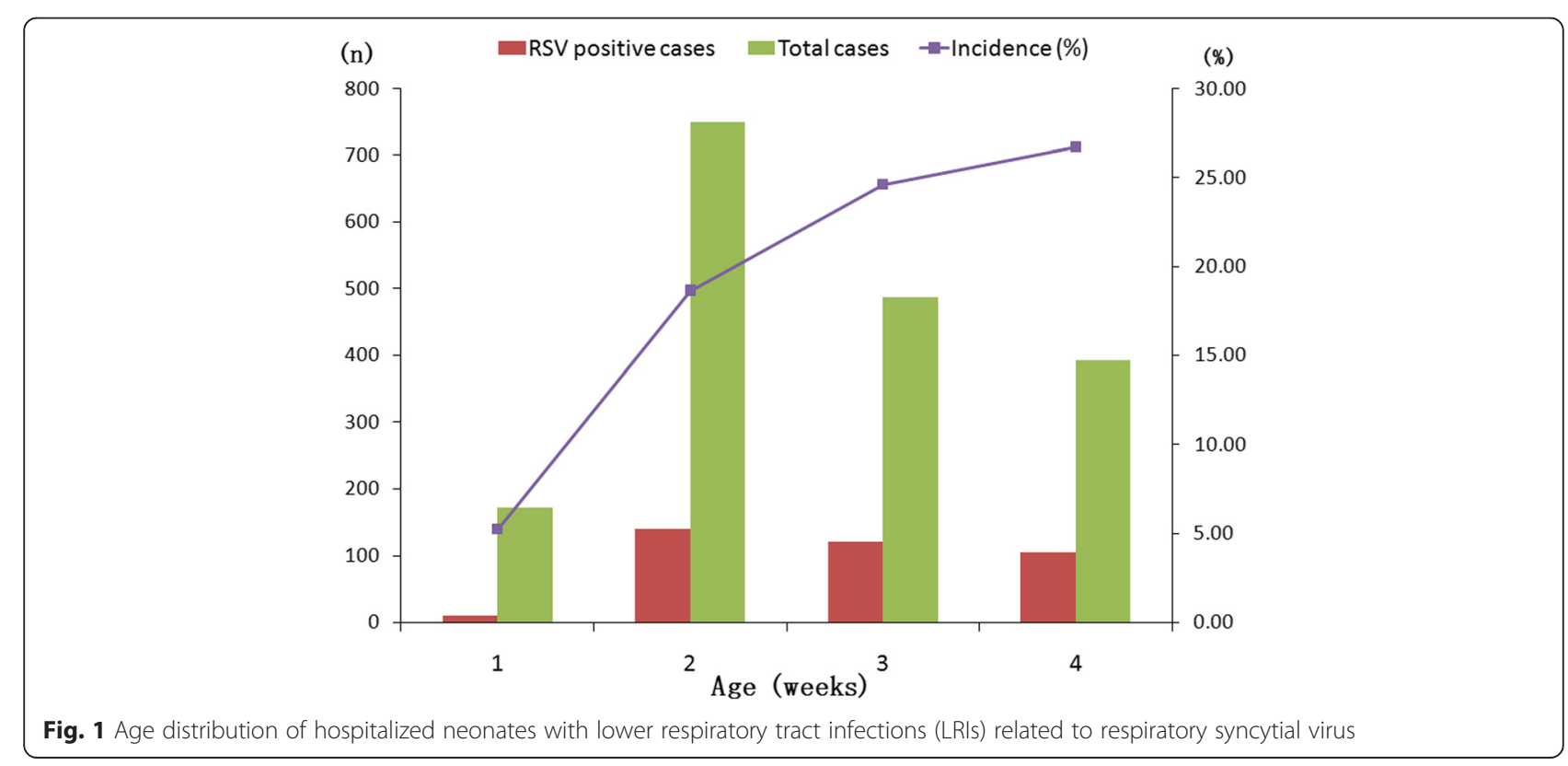




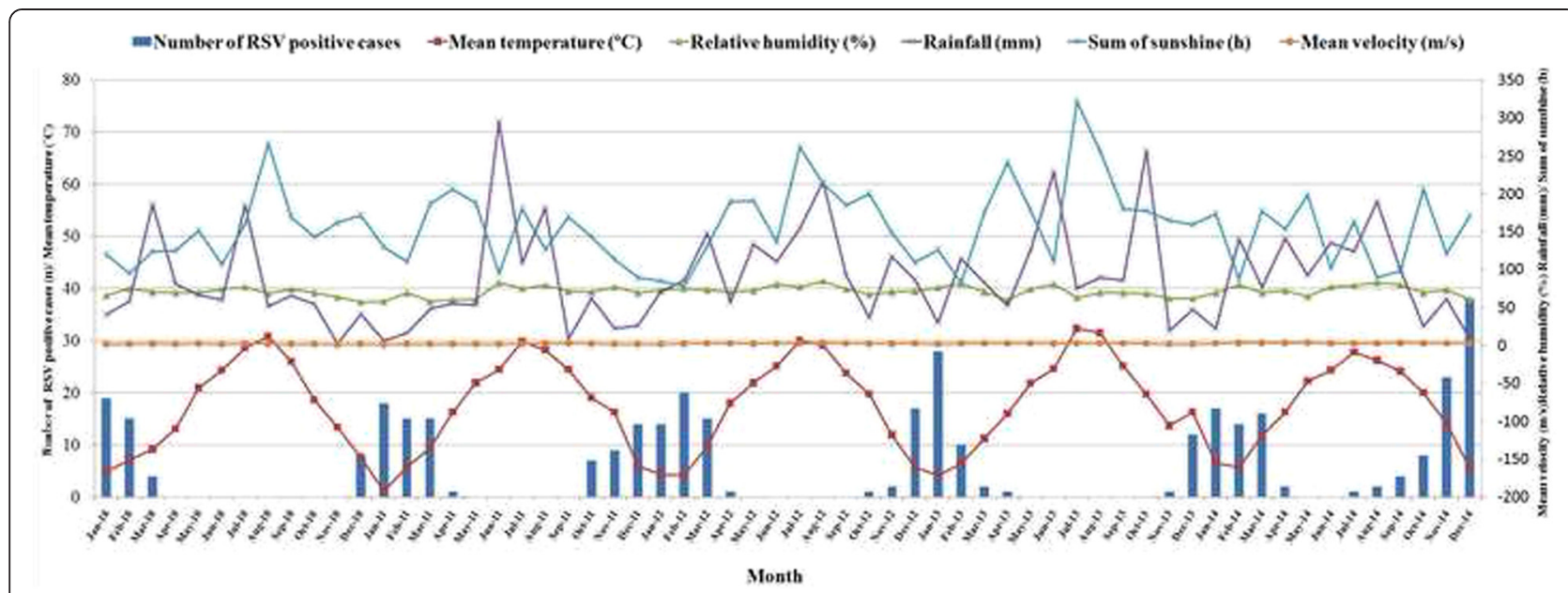

Fig. 2 Seasonal and monthly distribution of respiratory syncytial virus (RSV) infection and associations with climate factors for a 4-year period from January 2010 to December 2014. Meteorological data was measured hourly and then average daily values were calculated. Monthly means were calculated using the daily means for temperature, relative humidity, and wind velocity. Total rain and sum of sunshine were calculated as a total measurement for the month. Spring: March to May; summer: June to August; autumn: September to November; winter: December to February

stay. Only one neonate who presented with low birthweight (1950 g) and congenital heart disease died following respiratory and heart failure. No significant difference was shown in other parameters between RSV-positive neonates and those infected with other respiratory viruses.

In the present study, a total of 48 cases were hospitalized in NICU and care in NICU was considered as a marker of severe illness. Multivariate analysis by logistic regression revealed that prematurity, coinfection with other viruses, and underlying diseases were high risk factors of NICU stay (Table 4).

\section{Discussion}

The burden of hospitalization for children with community-acquired pneumonia was highest among the very young, and RSV is the most commonly detected virus causing pneumonia [7]. Infection with RSV is associated with mortality in hospitalized infants and young children [8], especially in infants less than 3 months old [9]. Exactly which parameters contribute to the seasonality of RSV in neonates and their comparative significances are the subject of ongoing intensive debate.
Few large sample studies have focused on neonates with RSV infection. This study describes the epidemiology of RSV in neonates for four consecutive years. In Suzhou, RSV is the most commonly detected virus in hospitalized neonates with LRIs, accounting for $20.74 \%$ of neonate respiratory infection. The incidence of RSV reported here was only slightly lower than that observed bythe study in Tunisia using DFA (23.1\%) [10]. In the present study, all neonates were $<28$ days old compared to their criteria of $<35$ days old in the Tunisia study. As shown in our study, the incidence of RSV-positive neonates increased with age, explaining why the incidence of RSV infection in this study was slightly lower than the Tunisia study. Interestingly, the incidence of infection in our study was higher than that seen in aneonatal medium care unit in Netherlands $(1.8 \%, 6 / 334)$ [11]. During the Netherlands study, information on symptomatic neonates were used regardless of whether the subjects tested positive for RSV. In constrast, only RSV-positive neonates were surveyed possibly explaining why RSV incidence in The Netherlands was reported lower than our own. Additionally, the difference in RSV incidence may be due to the use of different

Table 2 Associations between RSV incidence and climatic factors

\begin{tabular}{|c|c|c|c|c|}
\hline \multirow[t]{2}{*}{ Climate factors } & \multicolumn{2}{|c|}{ Spearman rank correlation coefficients } & \multicolumn{2}{|l|}{ Multivariate regression analysis } \\
\hline & $\overline{r_{s}}$ & $P$ value & Standardized beta coefficient & $P$ value \\
\hline Mean temperature $\left({ }^{\circ} \mathrm{C}\right)$ & -0.821 & $<0.0001$ & -0.758 & $<0.0001$ \\
\hline Relative humidity (\%) & -0.145 & 0.269 & 0.084 & 0.357 \\
\hline Total rainfall (mm) & -0.386 & 0.002 & -0.096 & 0.311 \\
\hline Sum of sunshine (h) & -0.406 & 0.001 & 0.024 & 0.814 \\
\hline Wind velocity $(\mathrm{m} / \mathrm{s})$ & -0.149 & 0.255 & 0.125 & 0.173 \\
\hline
\end{tabular}


Table 3 Comparison of Clinical and laboratory characteristics between neonates with RSV and viruses other than RSV

\begin{tabular}{|c|c|c|c|}
\hline \multirow[t]{2}{*}{ Clinical Parameters } & \multirow{2}{*}{$\begin{array}{l}\text { RSV- LRIS } \\
n=344\end{array}$} & \multirow{2}{*}{$\begin{array}{l}\text { Other viruses LRls } \\
n=131\end{array}$} & \multirow[t]{2}{*}{$P$ Value } \\
\hline & & & \\
\hline \multicolumn{4}{|l|}{ Demographic data } \\
\hline Age (median, IQR) & $17(12-22)$ & $17(13-23)$ & 0.002 \\
\hline Sex (male, \%) & $205(59.6)$ & $70(53.4)$ & 0.224 \\
\hline Birth weight (mean \pm std, g) & $3380.5 \pm 460.6$ & $3390.8 \pm 471.1$ & 0.820 \\
\hline Underlying condition $(n, \%)^{\mathrm{a}}$ & $35(10.2)$ & $11(8.4)$ & 0.558 \\
\hline \multicolumn{4}{|l|}{ Clinical symptoms } \\
\hline Cough $(n, \%)$ & $343(99.7)$ & $131(98.5)$ & 1.0 \\
\hline Fever $(n, \%)$ & $75(21.8)$ & $46(35.1)$ & 0.003 \\
\hline Wheezing ( $n, \%)$ & $34(9.9)$ & $12(9.2)$ & 0.812 \\
\hline Tachypnea $(n, \%)$ & $174(50.6)$ & $31(23.7)$ & $<0.001$ \\
\hline Dyspnea $(n, \%)$ & $68(19.8)$ & $17(13.0)$ & 0.084 \\
\hline Cyanosis $(n, \%)$ & $18(5.2)$ & $8(6.2)$ & 0.708 \\
\hline Refusal to feed $(n, \%)$ & $14(4.1)$ & $6(4.6)$ & 0.804 \\
\hline \multicolumn{4}{|l|}{ Physical examination } \\
\hline Moist rales $(n, \%)$ & $267(77.6)$ & $72(55.0)$ & $<0.001$ \\
\hline Wheezing rales $(n, \%)$ & $34(9.9)$ & $12(9.2)$ & 0.812 \\
\hline \multicolumn{4}{|l|}{ Laboratory tests } \\
\hline White blood cells & $9.1 \pm 2.7$ & $9.2 \pm 3.0$ & 0.777 \\
\hline C-reactive protein (median, IQR) & $0.9(0.3-2.6)$ & $0.6(0.1-2.1)$ & 0.061 \\
\hline Alanine transarninase increase $(n, \%)$ & $20(5.8)$ & $7(5.3)$ & 0.843 \\
\hline Creatine kinase-MB increase $(n, \%)$ & $257(74.7)$ & $85(64.9)$ & 0.033 \\
\hline Abnormal chest X-ray $(n, \%)$ & $307(89.2)$ & $67(51.4)$ & $<0.001$ \\
\hline \multicolumn{4}{|l|}{ Theraphy } \\
\hline Supplemental oxygen (n, \%) & $59(17.2)$ & $11(8.4)$ & 0.016 \\
\hline Mechanical ventilation $(n, \%)$ & $15(4.3)$ & $3(2.3)$ & 0.291 \\
\hline Duration of hospital days (median, IQR) & $10(9-12)$ & $8(7-10)$ & $<0.001$ \\
\hline
\end{tabular}

aUnderlying conditions: Congenital heart disease; Bronchopulmonary dysplasia; Bronchopulmonary malformation; Down Syndrome. RSV respiratory syncytial virus, $L R I$ lower respiratory tract infection, $I Q R$ inter-quartile ranges

methods for the detection of viral pathogen (DFA used in the Netherlands study, and PCR used in our study at Suzhou). Generally speaking, DFA is reported to be less sensitive than that of PCR testing. Surprisingly, the sensitivity of DFA in comparison to rt-RT-PCR was highest
(86 \%) during the first 3 days after the onset of symptoms, decreasing gradually until reaching $65 \%$ after the first week. The specificity of DFA in comparison to rtRT-PCR ranged between 99 and $100 \%$ irrespective of the date of collection [12].

Table 4 Risk factors of NICU stay in neonates with RSV related LRIs

\begin{tabular}{|c|c|c|c|c|c|}
\hline \multirow[t]{2}{*}{ Parameters } & \multirow{2}{*}{$\begin{array}{l}\text { NICU } \\
n=48\end{array}$} & \multirow{2}{*}{$\begin{array}{l}\text { Ward } \\
n=326\end{array}$} & \multirow[t]{2}{*}{ Crude OR (95 \% Cl) } & \multirow[t]{2}{*}{ Adjusted OR (95 \% Cl) } & \multirow[t]{2}{*}{$P$} \\
\hline & & & & & \\
\hline Sex (male, \%) & $28(58.3)$ & $196(60.1)$ & $0.929(0.502-1.718)$ & $0.692(0.353-1.357)$ & 0.284 \\
\hline Prematurity $(n, \%)$ & $10(20.8)$ & $10(3.1)$ & $8.316(3.252-21.265)$ & $6.679(2.279-19.580)$ & 0.001 \\
\hline Early neonate $(n, \%)^{\mathrm{a}}$ & $3(6.3)$ & $6(1.8)$ & $3.556(0.859-14.719)$ & $3.897(0.845-17.972)$ & 0.081 \\
\hline Low Birth Weight $(n, \%)$ & $5(10.4)$ & $8(2.5)$ & $4.622(1.446-14.771)$ & $1.651(0.427-6.388)$ & 0.468 \\
\hline Co-infection with other viruses $(n, \%)$ & $10(20.8)$ & $20(6.1)$ & $4.026(1.755-9.239)$ & $2.720(1.047-7.065)$ & 0.040 \\
\hline Underlying diseases $(n, \%)$ & $9(18.8)$ & $29(8.9)$ & $2.363(1.042-5.361)$ & $2.831(1.183-6.774)$ & 0.019 \\
\hline
\end{tabular}

${ }^{a}$ Early neonate indicates age less than one week. NICU neonatal intensive care unit, OR Odds Ratio, $R S V$ respiratory syncytial virus, $L R I$ lower respiratory tract infection 
In present study, when co-infection existed in conjunction with RSV, IV-A was found the most common co-virus. This is due to the winter/spring seasons seeing the peak of RSV and IV-A activity [13]. To our interest, Mycoplasma pneumoniae was also detected in neonates with LRIs $(2.5 \%, 45 / 1803)$ and $17.8 \%(8 / 45)$ of those cases were positive for RSV infection. Our recent study suggested that Mycoplasma pneumoniae was also a common cause of bronchiolitis in Suzhou [6]. This indicated that Mycoplasma pneumoniae may be an important pathogen in infants with LRIs.

We further report that RSV incidence increases with age, with RSV infection being more common in late neonates with respect to early ones. We presume that late neonates often have outdoor activities and are susceptible to an increased chance of contracting RSV infection. The increased risk of RSV infection may also be due to the waning of passively derived maternal antibodies. Regardless the cause, the first few days in nursery after birth should be taken into consideration with neonates presenting with LRIs.

In our study, the peak incidence occurred during thewinter and early spring months, as reported in our previous study with a subtropical climate $[14,15]$ and also expected in a temperateclimate $[16,17]$. In our present study, RSV could be detected during the summer months of 2014, which is unusual when compared to other summer months from 2010 to 2013; this phenomenon may be because of low temperatures reported during the summer of 2014, as shown in Fig. 2. However, RSV could circulate throughout summer seasons in Tunisia [10]. This different RSV activity might be caused by the different climate present in Tunisia.

Data generated from previous studies reveal a complex interaction of climate factors especially for temperature and humidity [18-21]. Some of the findings from this studyare similar to others. Monthly mean temperature, sum of sunshine and total rainfall were significantly correlated with the number of RSV-positive neonates with LRIs in this study. Taking the interaction of climate factors into consideration, only mean temperature was associated with RSV activity in neonates. On the contrary, low absolute humidity was independently associated with hospital admission of infants with lower respiratory tract infection due to RSV in northern Spain [21]. In a word, the trend of associations between climate factors and RSV activity varies with geographic locations [22]. In subtropical and temperate regions, RSV incidence is more consistently positively correlated with lower temperatures and higher relative humidity. However, no correlation was found between relative humidity and RSV activity in our study, owing to the stable relative humidity in subtropical Suzhou. Correlations between RSV activity, temperature, and relative humidity arevariable and inconsistent in tropical regions. Further study should be conducted to elucidate the variability between RSV activity and climate factors.

With regard to clinical profiles in neonates with LRIs due to RSV, several studies have focused on the clinical characteristics in neonates with RSV-related LRIs [10, 23-25]. Cho et al. [23] reported thatneonates with RSV-related LRIs had a greater incidence for the requirement of supplemental oxygen after birth, prolonging their hospitalization when compared to neonates infected with other respiratory viruses. As for the chest radiographic pattern in neonates with RSV-related LRIs, RSV infected neonatespresented with more abnormal patterns such as patches, consolidation and atelectasis when compared to non-RSV infected neonates from our study. A recent study [25] reported that neonates with a consolidation pattern on admission had a more severe disease phenotype, with greater risk of invasive mechanical ventilation which is consistent with our study.

To explore the risk predictors of NICU stay in neonateshospitalized with RSVinfection, amultivariable logistic regression model was applied. We found prematurity, coinfection, and underlyingdiseasewere independent risk factors for the severityof RSV infection which is in agreement with other studies [26, 27]. In the Tunisia study [10], prematurebirth and low birthweight might increase therisk of developing severe RSV disease. In contrast to our study, however, low birth weight was not associated with NICU stay. This may be due to the different definitions of low birth weight (2500 VS. $2000 \mathrm{~g})$. Identification of independent risk factors may be contributed to establish a threshold for passiveimmunization and admission to thehospital for high-risk neonates.

\section{Conclusions}

RSV is an important cause of LRIs in hospitalized neonates in Suzhou area with a subtropical climate, particularly during the winter season. Neonates positive for RSV are more prone to severe infection when compared to neonates infected with other common respiratory viruses. The identified predictors ofsevere diseasein neonates with RSV-related LRIs should be taken into consideration when implementing health interventions to newborns.

\section{Abbreviations}

RSV: Respiratory syncytial virus; LRI: Lower respiratory tract infection; CAP: Community-acquried pneumnia; NPA: Nasopharyngeal aspirate; DFA: Direct immunofluorescent assay; PCR: Polymerase chain reaction; IV: Influenza virus.

\section{Competing interests}

The authors declare that they have no competing interests. 


\section{Authors' contributions}

$\mathrm{ZC}$ and $\mathrm{CH}$ have made substantial contributions to conception and design. $\mathrm{LL}$ and $Y Y$ wrote the main manuscript text, collected and interpreted data. BY has been involved in RSV detection. ZX and XF collected clinical and laboratory data. MM, WJ and YW analyzed and interpreted the data. All authors reviewed the manuscript. All authors read and approved the final manuscript.

\section{Acknowledgements}

This work was supported by National Natural Science Foundation of China [Zhengrong Chen, grant number 81401296], Science and Technology Projects for the youth of Suzhou [Zhengrong Chen, grant number SYS201350, and Science and Technology Projects of Jiangsu Provincial Commission of Health and Family Planning [Zhengrong Chen, grant number Q201403].

\section{Author details}

'Department of Neonatology, Children's Hospital of Soochow University, Suzhou 215003, China. 'Department of Respiratory Disease, Children's Hospital of Soochow University, Suzhou 215003, China. ${ }^{3}$ Department of Clinical Lab, Children's Hospital of Soochow University, Suzhou 215003, China. ${ }^{4}$ Department of Cell Biology and Immunology, UNT Health Science Center at Fort Worth, Fort Worth, TX 76107, USA.

Received: 25 June 2015 Accepted: 28 September 2015

Published online: 15 October 2015

\section{References}

1. Nair H, Nokes DJ, Gessner BD, Dherani M, Madhi SA, Singleton RJ, et al. Global burden of acute lower respiratory infections due to respiratory syncytial virus in young children: a systematic review and meta-analysis. Lancet. 2010;375:1545-55.

2. Thorburn K. Pre-existing disease is associated with a significantly higher risk of death in severe respiratory syncytial virus infection. Arch Dis Child. 2009;94:99-103.

3. de Sierra TM, Kumar ML, Wasser TE, Murphy BR, Subbarao EK. Respiratory syncytial virus-specific immunoglobulins in preterm infants. J Pediatr. 1993;122:787-91

4. Hasan K, Jolly P, Marquis G, Roy E, Podder G, Alam K, et al. Viral etiology of pneumonia in a cohort of newborns till 24 months of age in Rural Mirzapur, Bangladesh. Scand J Infect Dis. 2006;38:690-5.

5. Chen ZR, Ji W, Wang YQ, Yan YD, Shao XJ, Zhang XL, et al. Etiology of acute bronchiolitis and the relationship with meteorological conditions in hospitalized infants in China. J Formos Med Assoc. 2014;113:463-9.

6. Wang Y, Hao C, Ji W, Yan Y, Shao X, Xu J. Bronchiolitis associated with Mycoplasma pneumoniae in infants in Suzhou China between 2010 and 2012. Sci Rep. 2015;5:7846.

7. Jain S, Williams DJ, Arnold SR, Ampofo K, Bramley AM, Reed C, et al. Community-acquired pneumonia requiring hospitalization among U.S. children. N Engl J Med. 2015:372:835-45.

8. Byington $\mathrm{CL}$, Wilkes J, Korgenski K, Sheng X. Respiratory syncytial virus-associated mortality in hospitalized infants and young children Pediatrics. 2015:135:e24-31.

9. Birkhaug IM, Inchley CS, Aamodt G, Ånestad G, Nystad W, Nakstad B. Infectious burden of respiratory syncytial virus in relation to time of birth modifies the risk of lower respiratory tract infection in infancy: the Norwegian Mother and Child Cohort. Pediatr Infect Dis J. 2013;32:e235-41.

10. Fodha I, Landolsi N, Vabret A, Sboui H, Trabelsi A, Freymuth F. Epidemiology and clinical presentation of respiratory syncytial virus infection in a Tunisian neonatal unit from 2000 to 2002. Ann Trop Paediatr. 2004;24:219-25.

11. Smit PM, Pronk SM, Kaandorp JC, Weijer O, Lauw FN, Smits PH, et al. RT-PCR detection of respiratory pathogens in newborn children admitted to a neonatal medium care unit. Pediatr Res. 2013;73:355-61.

12. Shafik CF, Mohareb EW, Youssef FG. Comparison of direct fluorescence assay and real-time RT-PCR as diagnostics for respiratory syncytial virus in young children. J Trop Med. 2011:2011:781919.

13. Učakar $V$, Sočan M, Trilar KP. The impact of influenza and respiratory syncytial virus on hospitalizations for lower respiratory tract infections in young children: Slovenia, 2006-2011. Influenza Other Respir Viruses. 2013:7:1093-102.

14. Chen Z, Zhu Y, Wang Y, Zhou W, Yan Y, Zhu C, et al. Association of meteorological factors with childhood viral acute respiratory infections in subtropical China: an analysis over 11 years. Arch Virol. 2014;159:631-9.
15. Zhang XL, Shao XJ, Wang J, Guo WL. Temporal characteristics of respiratory syncytial virus infection in children and its correlation with climatic factors at a public pediatric hospital in Suzhou. J Clin Virol. 2013;58:666-70.

16. Vandini S, Corvaglia L, Alessandroni R, Aquilano G, Marsico C, Spinelli M, et al. Respiratory syncytial virus infection in infants and correlation with meteorological factors and air pollutants.Ital. J Pediatr. 2013;39:1.

17. du Prel JB, Puppe W, Gröndahl B, Knuf M, Weigl JA, Schaaff F, et al. Are meteorological parameters associated with acute respiratory tract infections? Clin Infect Dis. 2009;49:861-8.

18. Yusuf S, Piedimonte G, Auais A, Demmler G, Krishnan S, Van Caeseele P, et al. The relationship of meteorological conditions to the epidemic activity of respiratory syncytial virus. Epidemiol Infect. 2007;135:1077-90

19. Meerhoff TJ, Paget JW, Kimpen JL, Schellevis F. Variation of respiratory syncytial virus and the relation with meteorological factors in different winter seasons. Pediatr Infect Dis J. 2009;28:860-6.

20. Tang JW, Lai FY, Wong F, Hon KL. Incidence of common respiratory viral infections related toclimate factors in hospitalized children in Hong Kong. Epidemiol Infect. 2010;138:226-35.

21. Lapeña S, Robles MB, Castañón L, Martínez JP, Reguero S, Alonso MP, et al. Climatic factors and lower respiratory tract infection due to respiratory syncytial virus in hospitalised infants in northern Spain. Eur J Epidemiol. 2005:20:271-6.

22. Tang JW, Loh TP. Correlations between climate factors and incidence-a contributor to RSV seasonality. Rev Med Virol. 2014;24:15-34.

23. Cho HJ, Shim SY, Son DW, Sun YH, Tchah H, Jeon IS. Respiratory viruses in neonates hospitalized with acute lower respiratory tract infections. Pediatr Int. 2013;55:49-53.

24. Thwaites R, Piercy J. Nosocomial respiratory syncytial virus infection in neonatal units in the United Kingdom. Acta Paediatr Suppl. 2004;93:23-5

25. Gonçalves A, Rocha G, Guimarães H, Fernandes PC, Proença E, Oliveira D, et al. Value of chest radiographic pattern in RSV disease of the newborn: a multicenter retrospective cohort study. Crit Care Res Pract. 2012;2012:861867.

26. Rodríguez DA, Rodríguez-Martínez CE, Cárdenas AC, Quilaguy IE, Mayorga LY, Falla LM, et al. Predictors of severity and mortality in children hospitalized with respiratory syncytial virus infection in a tropical region. Pediatr Pulmonol. 2014:49:269-76.

27. Zhang T, Zhu Q, Zhang X, Ding Y, Steinhoff M, Black S, et al. Clinical characteristics and direct medical cost of respiratory syncytial virus infection in children hospitalized in Suzhou. China Pediatr Infect Dis J. 2014;33:337-41.

\section{Submit your next manuscript to BioMed Central and take full advantage of:}

- Convenient online submission

- Thorough peer review

- No space constraints or color figure charges

- Immediate publication on acceptance

- Inclusion in PubMed, CAS, Scopus and Google Scholar

- Research which is freely available for redistribution

Submit your manuscript at www.biomedcentral.com/submit 